\title{
त्री \\ Anotações para uma leitura contemporânea de As mecânicas de Galileu Galilei
}

\author{
Julio Celso Ribeiro de Vascongelos

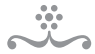

RESUMO

O presente artigo é uma apresentação dos desenvolvimentos de As mecânicas, trabalho pioneiro sobre os instrumentos mecânicos composto por Galileu Galilei $(1564-1642)$ nos anos 1590. Esta apresentação tem como objetivo marcar para o leitor contemporâneo as especificidades das conceituações e argumentações do texto de Galileu, anteriores às formulações e sistematizações que constituem a chamada "física clássica", em cujo referencial esse leitor foi educado.

Palavras-chave • Balança. Alavanca. Estática. Dinâmica. Mecânica. Galileu,

O Trattato delle meccaniche (Tratado das mecânicas) - ou simplesmente Le meccaniche (As mecânicas), como é mais conhecido - foi composto por Galileu Galilei $(1564,-164,2)$ entre 1593 e 1602, possivelmente para o ensino acadêmico no Studio de Pádua e para os cursos particulares que ministrava, ${ }^{1}$ e não foi publicado por ele em vida. Houve, porém, ampla circulação de manuscritos, o que levou Marin Mersenne a fazer uma versão em francês, com o título Les mechaniques de Galilée (As mecânicas de Galileu), que foi publicada enquanto Galileu ainda era vivo, em 1634. Somente em 1649 surgiu uma edição completa em italiano, impressa em Ravena por Luca Danesi. Esta, bem como outras edições posteriores e um conjunto de manuscritos, quase todos do século xvII, constituíram a base sobre a qual Antonio Favaro estabeleceu o texto que fez publicar em 1891 no segundo volume das Opere de Galileu.

Essa obra fundadora da estática moderna, cuja tradução para o português é apresentada neste número de Scientiae Studia com o título As mecânicas, pode dizer-se dividida em três partes, sendo a primeira dedicada a apresentar os fundamentos teóricos e a tratar dos "instrumentos cuja natureza se pode reduzir à balança", a saber, a balança romana, a alavanca, o eixo da roda e o cabrestante. A segunda parte, que trata das talhas, o faz a partir da consideração do que hoje se chama alavanca inter-resistente, embora rapidamente reduza essa alavanca àquela primeira, a interfixa, instrumento essencialmente idêntico à balança. A terceira parte, dedicada aos parafusos, entende esses instrumentos, como se verá mais abaixo, como planos inclinados. Porém, antes 
de apresentar essa perspectiva, Galileu deduz as propriedades dos planos inclinados a partir de uma balança, o que dá razão a Romano Gatto, quando afirma que "Galileu reduzirá o estudo das demais máquinas simples ao da balança” (Gatto, 2001a, p. 199). As mecânicas concluem com um adendo sobre a "força da percussão".

Não é incorreto dizer que a primeira parte parece igualmente dedicada a denunciar os "enganos" daqueles que crêem que se pode "com pouca força mover e levantar grandíssimos pesos”. À primeira vista, parece que a formulação acima de Galileu é que é um engano, pois, afinal, as aulas de estática nos ensinaram que o peso é uma força (a gravitacional) e que as máquinas simples, como a balança ou a alavanca, são úteis porque propiciam equilíbrio entre forças desiguais. Mas é preciso que se tenha em mente que Galileu pensa e escreve antes da sistematização final que constituirá a chamada física clássica, aliás, antes mesmo de sua obra científica mais madura, os Discorsi e dimostrazioni matematiche intorno a due nuove scienze (Argumentos e demonstrações matemáticas sobre duas novas ciências) (1638), de modo que é preciso conceder-lhe que elabore seus ensinamentos em um quadro conceitual diverso daquele que hoje se emprega nas aulas de física, embora as palavras que usa frequentemente sejam as mesmas.

O que ele tem em mente, ao denunciar aqueles "enganos", logo se esclarece, quando ensina que as "comodidades" trazidas pelas máquinas só são compreendidas levando em consideração, além do peso e da força (ou "potência"), também a distância e o tempo, "tempo que retorna na própria coisa com a presteza e velocidade do movimento" (EN, 2, p. 156). Para explicar isso a seu leitor, Galileu imagina que uma força pequena eleva um grande peso quando este é dividido "em muitas partezinhas, cada uma das quais não sendo superior à força, e transferindo-se uma de cada vez", de modo que a força efetua diversas vezes aquele movimento que, conforme Galileu vê, "terá sido medido por todo o peso de uma só vez" (EN, 2, p.156). É interessante antecipar o final dessa explicação, porque nele se exemplificam comparações que não se encontrarão mais nos quadros da física clássica:

Do que parece a velocidade da força ter sido tantas vezes superior à resistência do peso, quantas vezes esse peso é superior à força, pois que naquele tempo no qual a força movente mediu muitas vezes o intervalo entre os términos do movimento, esse móvel o acaba por ter passado uma só vez; nem por isso se deve dizer ter sido superada grande resistência com pequena força, fora da constituição da natureza. Então, somente se poderia dizer ter-se superado o propósito natural, quando a menor força transferisse a maior resistência com igual velocidade de movimento, segundo o qual essa [resistência] caminha; o que afirmamos ser absolutamente impossível de fazer-se com qualquer máquina que se queira, imaginada ou que imaginar se possa (EN, 2, p. 156-7; grifos meus). 
É digno de nota que, no trecho destacado, Galileu aparentemente enunciou a seguinte proporção:

$$
\text { velocidade : resistência :: peso : força. }
$$

Usamos a representação $A: B:: C: D$, porque não podemos associar uma proporção a uma igualdade de frações $(A / B=C / D)$, como é usual hoje, no referencial matemático em que Galileu se move, dado pelos Elementos de Euclides, onde as razões não são frações. Mas é também digno de nota que, na própria teoria euclidiana das proporções, não se concebiam razões entre "magnitudes" diferentes, de modo que é de estranhar uma razão envolvendo velocidade e resistência.

Não é esse o único momento em que Galileu compara velocidade e resistência; por exemplo, mais adiante em suas análises, no item "Algumas advertências acerca das coisas ditas", ele volta a fazê-lo. Mas não interessa aqui esgotar as instâncias de comparações ou proporções que causam estranhamento ao leitor moderno; importa, através desse exemplo, solicitar a esse leitor que não apresse julgamentos anacrônicos ao percorrer as páginas de As mecânicas de Galileu.

Outro termo de uso corrente na física atual é "momento", concebido como uma grandeza diferente da força, na medida em que seu caráter dimensional é dado pelo produto: força x comprimento. Mas, nas definições que apresenta após suas considerações concernentes às "comodidades" dos instrumentos mecânicos (cujo sabor, digamos assim, se pode apreciar com a leitura da tradução a seguir), Galileu traz uma distinção mais esmaecida. Vejamos:

Chamemos, portanto, gravidade àquela propensão de mover-se naturalmente para baixo, a qual se encontra causada, nos corpos sólidos, pela maior ou menor quantidade de matéria, da qual são constituídos.

Momento é a propensão de ir para baixo, causada não tanto pela gravidade do móvel, quanto pela disposição que possuem entre si os diferentes corpos graves (corpi gravi); momento mediante o qual se verá muitas vezes um corpo menos grave contrapesar outro de maior gravidade, tal como se vê na balança romana um pequenino contrapeso levantar outro peso grandíssimo, não por excesso de gravidade, mas antes pela distância do ponto em que é sustentada a balança; distância que, em conjunção com a gravidade do peso menor, aumenta-lhe o momento e o ímpeto de ir para baixo, com o qual pode exceder o momento do outro grave maior. $\mathrm{O}$ momento é, portanto, aquele ímpeto de ir para baixo, composto de gravidade, posição e de outro, do que possa ser causada tal propensão" (EN, 2, p. 159-60). 
Como se pode ler, tanto "peso" como "momento" denotam propensões de mover-se para baixo, o que vai permitir que, no desenvolvimento da teoria, sejam diretamente comparados. Galluzi entende que "momento" denota um conceito que dá conta da "variação da eficácia" do peso (Galluzi, 1979, p. 205). Quanto a "ímpeto" - que no primeiro uso na citação acima parece ser algo distinto de "momento" e no segundo uso parece ser sinônimo - Galluzi não tem dúvida: para ele "o ímpeto representa o efeito dinâmico do momento, o qual permanece uma 'propensão', uma condição abstrata" (Galluzi, 1979, p. 205). O que parece difícil de sustentar é a afirmação de Romano Gatto, para quem "a definição de momento dada por Galileu é a definição habitual de momento estático" (Gatto, 2001a, p. 200), na medida em que, na física clássica, são diferentes as dimensões de momento $\left(M L_{2} T-2\right)$ e de peso (MLT-2), enquanto na definição de Galileu ambos são propensões de mover-se para baixo.

Galileu também define "centro de gravidade" e associa três "suposições" a essa noção, fazendo-o de uma maneira que não causa estranhamento ao leitor hodierno, como a leitura da tradução poderá atestar. Vale antecipar a terceira suposição:

Suponha-se finalmente que o centro de gravidade de dois corpos igualmente graves está no meio daquela linha reta que une os dois referidos centros; ou, em verdade, dois pesos iguais suspensos a distâncias iguais, terão o ponto de equilíbrio na união comum dessas distâncias iguais (...) (EN, 2, p. 160).

A figura que Galileu usa para ilustrar sua suposição e o texto desta esclarecem que as distâncias iguais são concebidas colineares e perpendiculares às verticais que passam pelos respectivos pesos e o "centro comum das coisas graves", isto é, o centro da Terra. É com base nessa suposição que vai apresentar a

explicação de um princípio comuníssimo e principalíssimo de boa parte dos instrumentos mecânicos, demonstrando como pesos desiguais pendentes de distâncias desiguais pesarão igualmente, sempre que ditas distâncias tenham proporção inversa daquela que têm os pesos (EN, 2, p. 161).

Para essa primeira demonstração - que, segundo Galluzi (1979, p. 207), tem como modelo as demonstrações de Arquimedes em seu Equilíbrio dos planos - Galileu faz uso da figura abaixo, que ilustra um sólido cilíndrico que nomeia CDFE (ou simplesmente $C F$ ), e explica, com base naquela suposição, que tal sólido estaria em equilíbrio se suspenso pelo ponto $G$, o ponto médio da "linha $A B$, igual à altura $[C D$ ou $E F]$ do sólido" (EN, 2, p. 161). 


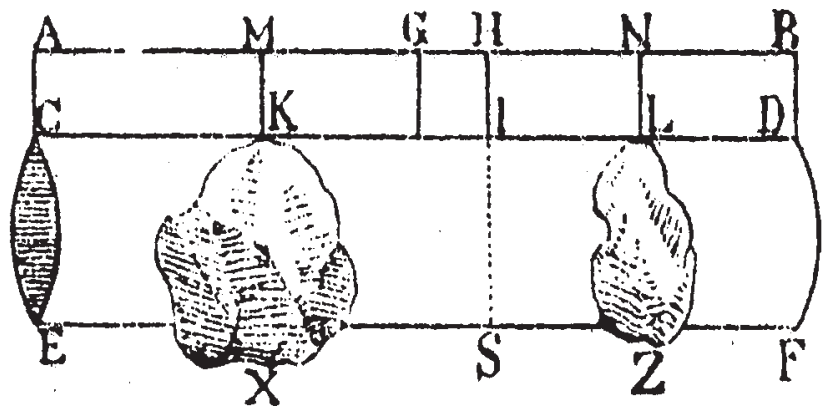

Com habilidade, Galileu argumenta que se tal sólido fosse "cortado segundo a linha IS" as duas partes desiguais se equilibrariam, quando respectivamente sustentadas pelos "liames" $N L$ e $M K$, colocados de tal modo que $L I=L D$ e $K C=K I$. Posto isso, propõe-se a demonstrar que "a proporção que se encontra entre o peso CS e o peso $S D$ é aquela que se encontra entre a distância $N G$ e a distância GM" ou, em nossos termos,

PCS : PSD :: NG : GM. Os passos de demonstração são os seguintes:

(1) Como $M H=1 / 2 H A$ e $N H=1 / 2 H B$ então $M N=1 / 2 A B$;

(2) mas também $\mathrm{BG}=1 / 2 A B$, de modo que $M N=B G$;

(3) "retirando [destas duas linhas] a parte comum $G N$ ", isto é, fazendo $M N-G N=B G-G N$ obtém-se $M G=N B$;

(4) mas também $N H=N B$ (pois $N$ é ponto médio de $H B$ ), de modo que $M G=N H$;

(5) "acrescentada comumente a parte $G H$ ", isto é, se se faz $M G+G H=N H+G H$ obtém-se $M H=N G$;

(6) sobre as igualdades finais dos passos (4) e (5) pode-se escrever a proporção $N G: M G:: M H: N H$;

(7) mas $M H: N H:: K I: I L$ (uma vez que se têm $M H=K I$ e $N H=I L$ ); dobrando as magnitudes da última razão, a proporção fica $M H: N H:: 2 . K I$ : 2.IL, ou seja $M H: N H:: C I: I D$;

(8) como a razão entre as "alturas" CI e ID é a mesma dos pesos PCS e PSD (porque são iguais as áreas das bases e também as densidades dos dois cilindros, Galileu hoje poderia dizer), tem-se a proporção $C I$ : ID :: PCS : PSD;

(9) assim, $N G: G M:: P C S: P S D$, como se queria demonstrar.

Para que o leitor de hoje entenda adequadamente o último passo, é preciso que conheça uma operação que a teoria euclidiana das proporções possibilita (e que Galileu, confiante de que fala para quem a conhece, não explicita), operação denominada ex aequalis, algo como "tirar a (razão) igual”. Essa operação que o passo (9) efetua fica evidente, se alinharmos as proporções finais dos passos (6), (7) e (8), 
$N G: M G:: M H: N H ; M H$ : NH :: CI : ID; CI : ID :: PCS : PSD

e retirando as razões iguais:

$$
N G: M G:: P C S: P S D
$$

Feita a demonstração, Galileu apresenta "outra congruência e probabilidade, pela qual se pode razoavelmente confirmar a mesma verdade" (EN, 2, p. 163). Com o auxílio de uma figura, que ilustra uma balança de braços desiguais $B C$ e $A C$ em equilíbrio, com $B C>A C$, explica que um dos pesos, o colocado em $B$, por exemplo, levanta o outro (colocado em $A$ ) se lhe for acrescentado "um mínimo momento de gravidade". E como o percurso de $B$ é maior que o de $A$, ambos atravessados no mesmo intervalo de tempo, "nem será maravilhoso nem alheio à constituição natural, que a velocidade do movimento do grave $B$ compense a maior resistência do peso $A$, enquanto ele se move preguiçosamente (...) e o outro descende velozmente (...)" (EN, 2, p. 164).

Segundo Galluzzi (1979, p. 208), esta é uma demonstração "dinâmica", empregando o método das velocidades virtuais, em contraposição ao "método rigorosamente estático-geométrico" da primeira demonstração. Também aqui é digno de nota que acabamos de ler outra comparação entre velocidade e resistência. É novamente necessário lembrar que a análise dimensional e o sistema internacional de unidades ainda não existiam no século xvıı, de modo que não devemos fazer exigências anacrônicas de rigor ao trabalho pioneiro de Galileu, sendo necessário respeitosa consideração para sua declaração de compensação velocidade-resistência.

Outra coisa que vale ressaltar no trecho acima citado é que nele, de novo, Galileu faz enfática recusa da "maraviglia”. Não é a última: a seguir, quando trata da balança romana (que traz um pequeno contrapeso móvel) e da alavanca, ambos diretamente derivados da demonstração acima parafraseada, Galileu volta a insistir que a utilidade que se obtém de um instrumento como a alavanca "não é aquela da qual se persuadem os mecânicos vulgares, isto é, que se acaba por superar e, de certo modo, enganar a natureza, vencendo com pequena força uma resistência grandíssima” (EN, 2, p. 166).

Há mais dois instrumentos diretamente conectados com aquela primeira demonstração, o eixo da roda e o cabrestante, ambos dependendo "imediatamente da alavanca, não sendo antes outra coisa que uma alavanca perpétua" (EN, 2, p. 167). Não é conveniente aqui comentar como Galileu justifica tal afirmativa. Interessa-nos citar mais um ataque àqueles "enganos" denunciados desde o início de As mecânicas:

Tanto neste, como no outro instrumento, nota-se aquilo que várias vezes se afirmou: a saber, a utilidade que dessas máquinas se obtém não é aquela na qual o 
Anotações para uma leitura gontemporânea de As mecânicas de Galileu

vulgo acredita comumente, enganando-se, acerca dos mecânicos, isto é, que se possa, defraudando a natureza, com máquinas superar a sua resistência, ainda que grande, com pequena força (EN, 2, p. 170).

Por que essa preocupação quase obsessiva com tais "enganos”? Para Romano Gatto, essas denúncias de As mecânicas seriam reverberações de um tenso episódio, em que Galileu demonstrou ser irrealizável um projeto de uma máquina para retirar lama das docas de Livorno, projeto que era um presente de Giovanni de Médici, filho natural de Cosimo I, ao Grão Duque Ferdinando i (Gatto, 2001a, p. 192). Por outro lado, em seu artigo no presente número de Scientiae Studia, Pablo Mariconda propõe uma explicação alternativa, menos retumbante. Ao denunciar aqueles "enganos acerca dos mecânicos", Galileo estaria recusando o ponto de vista que se apresenta nas Questões mecânicas aristotélicas, onde as máquinas - em consonância com o sentido do grego mechanai, a saber, o de "expedientes" - são vistas como ardis para produzir benefício para a humanidade "a despeito da natureza". O fato é que a preocupação com a denúncia daqueles "enganos" é notável característica do que aqui se entende constituir a primeira parte de As mecânicas, dedicada aos instrumentos "cuja natureza se pode reduzir à balança, tomada como seu princípio e fundamento" (EN, 2, p. 171).

Passemos ao trecho que aqui se vê constituindo a segunda parte de As mecânicas, dedicada ao tratamento das talhas - associações envolvendo uma ou mais polias móveis. A ruptura com a primeira parte não é total. Embora no início do capítulo intitulado "Das talhas", Galileu afirme que estas envolvem "outro modo de usar a alavanca", modo a que hoje se associa o termo "inter-resistente", este acaba reduzindo-se ao primeiro modo, o "interfixo". A figura ilustra o segundo modo, com a "força potente" ainda aplicada em uma extremidade, $C$, o apoio, porém, não mais entre as extremidades mas em uma delas, $A$, dando seu lugar ao peso $D$ a elevar, suspenso, assim, em um ponto intermediário $B$ (daí o nome "inter-resistente").

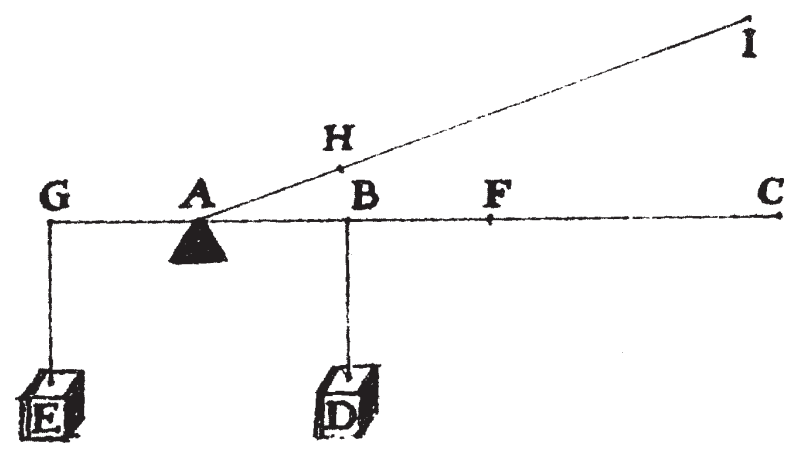

Também se vê na figura o recurso do qual Galileu faz uso para a redução ao primeiro modo de usar a alavanca: "tomar" um peso $E=D$ na extremidade $G$ de um prolongamento imaginário $G A$ de $C A$, concebido de modo que $G A=A B$. Com tal artifício, Galileu rapidamente pode concluir que (o destaque em itálico é nosso) a "força em $C$ iguala o momento do peso $D$, sempre que com ele tenha aquela proporção que a distância $B A$ tem para a distância $C A$ " (EN, 2, p. 172). Dessa maneira, Galileu obtém proporção semelhante e equivalente à da balança e do primeiro modo da alavanca. 
Posto isso, a explicação de como as talhas propiciam comodidade é baseada nesse segundo modo de usar a alavanca. A consideração da única polia móvel da mais simples delas, polia destacada na figura abaixo, se faz apontando que, como o peso $G$ está suspenso na "caixa ou armadura $B L C$ " da polia, tudo se passa como se $G$ pendesse do ponto $E$, médio do diâmetro $B E C$ da polia.

Já a extremidade $B$ comporta-se como um apoio fixo (embora se mova), na medida em que está diretamente conectado à extremidade $A$ da corda, extremidade "fixada a algum sustento estável" (EN, 2, p. 173). Ou seja, o diâmetro $B E C$ da polia móvel nada mais é do que uma alavanca interresistente que se move verticalmente. E como $C B$, a distância da força ao apoio $B$, é o dobro da distância $C E$ entre o apoio e ponto de que "pende o grave", então se pode ter por certo que, "por aquilo que acima se demonstrou, a força terá para o peso a mesma proporção que a distância $E B$ tem para a dis-

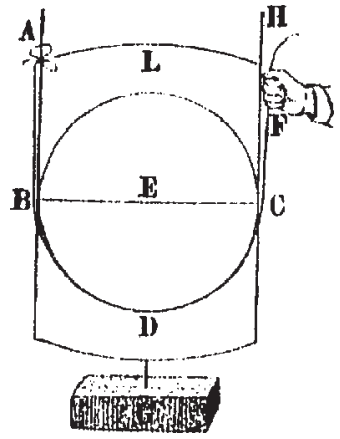
tância BC; por isso, será a metade desse peso" (EN, 2, p. 174).

Esse é o esquema básico da mais simples das talhas, que serve para "duplicar a força". A seguir, Galileu analisa outras talhas que fazem crescer a força de acordo com "multiplicidade segundo os números pares" (EN, 2, p. 175), e de suas análises conclui que para multiplicar a força por um fator 2.n é preciso associar $n$ polias móveis (sua linguagem não é essa, evidentemente).

A consideração da multiplicação da força "segundo os números ímpares" resume-se apenas à "proporção tripla", para o que Galileu imagina, uma vez mais, uma alavanca inter-resistente $A C B$, fixa em $A$ e tendo um peso $D$ suspenso em $C$. A novidade agora é que há duas forças potentes, ambas para cima, uma aplicada em $B$ e outra em $C$, de modo que Galileu pode dizer "que cada uma dessas potências tem momento igual à terça parte do peso D" (EN, 2, p. 177). A citação não deixa lugar para dúvida: Galileu está mesmo comparando peso e momento, o que não mais se fará na formulação posterior da física clássica, quando "momento" adquire significado distinto do significado de "força" ou "peso".

No tratamento do parafuso e da cóclea de Arquimedes, Galileu vai introduzir uma nova perspectiva explicativa: o plano inclinado. Inicia suas reflexões explicando que, se colocada sobre um plano cuja inclinação fosse de apenas "um cabelo", uma bola já teria movimento espontâneo de descida, enquanto no plano horizontal "fica como que indiferente e dúbia entre o movimento e o repouso". Dessa consideração, Galileu se permite "tomar como axioma indubitável (...) que os corpos graves, removidos todos os impedimentos externos e adventícios, podem ser movidos no plano do horizonte por qualquer mínima força" (EN, 2, p. 180). 
Já se pode vislumbrar aqui o princípio de inércia, fundamento primeiro da física clássica. Este, aliás, também já se entrevia no tratamento com velocidades virtuais, que acompanhamos mais acima, de uma balança de braços desiguais $B C$ e $A C$ em equilíbrio, com $B C>A C$, quando Galileu afirmava que "um mínimo momento de gravidade" acrescentado ao peso em $B$ levanta o outro colocado em $A$ (cf. EN, 2, p. 163-4).

Mas, como foge ao escopo do presente trabalho a discussão da contribuição de Galileu para o estabelecimento do princípio de inércia, limitar-nos-emos aqui a apontar que o "axioma indubitável" citado acima serve, em As mecânicas, apenas para estabelecer, através de uma argumentação não-formalizada, que a força necessária para fazer subir um corpo sobre um plano inclinado aumenta quando aumenta a inclinação do plano. Isso, claro, não satisfaz a Galileu, que logo promete a seu leitor demonstrar que "o mesmo peso é movido sobre o plano inclinado (...) por uma força menor que na perpendicular (...) (onde é alçado por força igual a si mesmo)" (EN, 2, p. 180-1), segundo a proporção em que a altura do plano é menor que seu comprimento (que é também o comprimento da perpendicular em questão).

A demonstração se faz sobre a figura abaixo reproduzida, que esquematiza uma "alavanca ou balança móvel $[A C]$ em torno do centro $B$ ", com dois pesos, em $A$ e em $C$, de momentos iguais". Mas, argumenta Galileu, se o braço $B C$ for inclinado para baixo até $F$, o "momento do peso em $F$ será como se pendesse da linha $K B$ ". Analogamente, se o braço for girado até $L$, seu momento "será como se pendesse da distância $B M$, segundo a linha $M L$ " (cf. EN, 2, p. 181-2).

Agora, em passagem argumentativa em direção aos planos inclinados, Galileu vai dizer que o mesmo vale se a circunferência CFLI for uma superfície, sobre a qual descesse o móvel, apoiando-se sobre ela. E que em F o móvel está

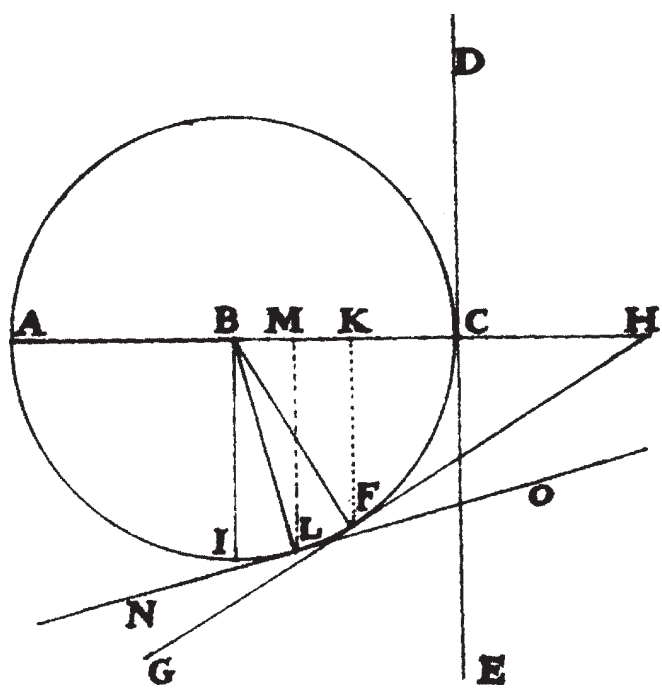
"como se estivesse no plano elevado segundo a linha tangente GFH" (EN, 2, p. 182). Note-se que $F$ é vértice de dois triângulos retângulos, o triângulo $B F H$, retângulo em $F$, e o triângulo $B K F$, retângulo em $K$, com o ângulo em $B$ comum aos dois. Com isso, os dois triângulos são semelhantes e, como a razão entre os catetos menores é a mesma que a razão entre os catetos maiores, temos $B F: K B:: H F: K F$. Mas como $B F=B C$ (já que são ambos raios da circunferência), a razão $B F: K B$ é, como se explicou há pouco, a razão entre o "momento total e íntegro" e o momento em $F$, de modo que a semelhança de triângulos permite a Galileu concluir que 
Mtotal : MF :: HF : HK.

O golpe final: Galileu volta sua atenção para o triângulo HFK, gira-o em 180 , convertendo-o na figura de um plano inclinado $F H$ com altura $F K$ e se permite concluir "esta proposição universal: sobre o plano inclinado, a força tem para o peso a mesma proporção que a perpendicular do término do plano até a horizontal tem para o comprimento desse plano" (EN, 2, p. 183).

É digno de nota, em primeiro lugar, que Galileu prometeu uma demonstração sobre planos inclinados de mesmo comprimento de uma perpendicular mas, no resultado final que apresentou, o plano inclinado é mais extenso que a perpendicular correspondente; em segundo lugar, que sua argumentação deu como assentes equivalências físicas que lhe permitiram passar da consideração da balança $A B C$ para o plano inclinado $H F$.

Nesse momento de As mecânicas, Galileu está pronto para "retornar" ao parafuso, o propósito primeiro das considerações acima, o que faz imaginando um plano inclinado que é movido horizontalmente, fazendo subir um móvel que desliza sobre ele: o móvel não se desloca horizontalmente, mas está livre para se mover verticalmente conforme o plano inclinado se desloca sob ele, empurrando-o, assim, para cima. É dessa forma, ensina Galileu, que se gera um parafuso (de eixo vertical), cuja rosca ou "verme" é entendido como um plano inclinado que se encurva, deforma-se, de modo tal a envolver o cilindro que constitui o corpo do parafuso. Assim, conforme o cilindro gira, esse "verme" conduz para cima um móvel que possa deslizar verticalmente sobre ele. Deixemos para a leitura de As mecânicas a fruição de como Galileu, também para o plano inclinado, "não deixa em silêncio aquela consideração, a qual se disse, ao início, ser necessária de existir em todos os instrumentos mecânicos, a saber, que quanto se ganha em força por meio deles, outro tanto se perde no tempo e na velocidade" (EN, 2, p. 185).

Mas vale registrar que, ao explicar mais detalhadamente o funcionamento do parafuso de Arquimedes, quando concebido para elevar água, Galileu o trata como "invenção que não só é maravilhosa, como também miraculosa”. Nesta aplicação, hoje conhecida como "parafuso ou cóclea de Arquimedes", o verme é substituído por um tubo que tem um trecho inferior imerso na água a elevar, conforme se gira o parafuso. Galileu vê tal parafuso como "maravilhoso" e "miraculoso" porque se dá conta que "a água sobe no parafuso descendo continuamente", na medida em que aquela parte do tubo que capta a água deve estar, além de completamente imersa, inclinada de modo tal que a água que a percorre faz um movimento de descida. 
Para entender porque o mesmo Galileu que se empenhou em denunciar os "enganos" dos que se encantam com a alavanca e outras máquinas simples não pode, honestamente, deixar de se maravilhar com a cóclea de Arquimedes, devemos atentar para o fato de que todas as máquinas anteriores podem ser tratadas teoricamente de modo rigorosamente estático, enquanto tal consideração não se pode fazer para a cóclea de Arquimedes. De fato, nos cursos contemporâneos de estática, seja no nível médio, seja nas disciplinas introdutórias dos cursos de física ou engenharia, alavancas e polias não são estudadas efetuando os movimentos que as tornam úteis mas como arranjos estáveis de corpos imóveis em equilíbrio estático. É por essa razão que as condições de equilíbrio de forças e momentos (ou torques) são suficientes para o entendimento de tais máquinas, com o movimento sendo um adendo elegante que as tira do domínio puramente teórico.

Essa perspectiva o leitor contemporâneo pode vislumbrar no tratamento de Galileu para as alavancas e polias pois, embora atento e interessado todo o tempo no movimento das peças das máquinas, nosso cientista as analisa, em última instância, do mesmo modo que hoje o fazemos nas aulas de estática (o nome não é casual !). Mesmo no caso do plano inclinado, a análise teórica é rigorosamente estática porque "à força, para mover o peso, basta que insensivelmente supere aquela que o sustém" (EN, 2, p. 183). Ora, tal perspectiva não se aplica à cóclea de Arquimedes, para a qual é preciso fazer considerações de energia, entendendo que, com a rotação do parafuso, parte da energia cinética se converte em acréscimo da energia potencial da água que, assim, sobe.

Galileu, nos albores do século xvıı, não está em posse de tal perspectiva, daí maravilhar-se com a invenção de Arquimedes. Enquanto tratava o plano inclinado de modo estático, podia, com justeza, manter-se distante do "miraculoso" mas agora, ao tentar entender de modo também rigoroso a cóclea de Arquimedes, gerada a partir do mesmo plano inclinado, não há como não ficar desconcertado. Mas nosso cientista não ficará quedado em espanto perante a invenção de Arquimedes. Não por acaso, é justamente sobre o plano inclinado que, anos depois, virá a enunciar o que se constituirá como o princípio único da ciência do movimento dos Discorsi de 1638:

o autor supõe e postula como verdadeiro somente um princípio, a saber : os graus de velocidade alcançados por um mesmo móvel em planos diferentemente inclinados são iguais quando as alturas desses planos também são iguais (Galilei, 1988, p. 167). 


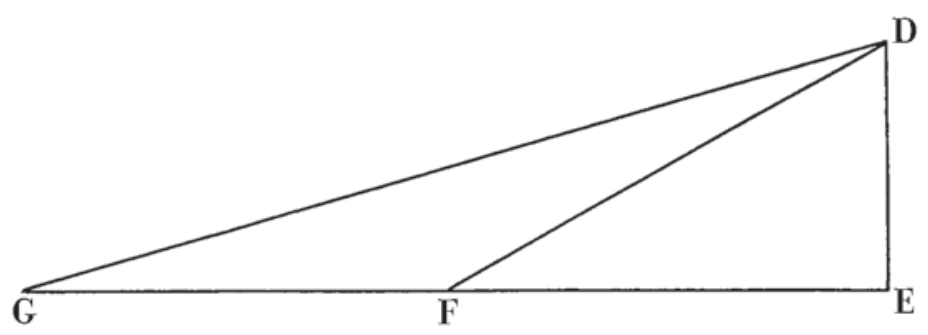

Afigura acima ilustra tal "princípio": se se imagina um mesmo móvel caindo sempre a partir do repouso em $\mathrm{D}$, os graus finais de velocidade em $\mathrm{E}, \mathrm{F}$ ou $\mathrm{G}$ serão os mesmos.

É notável que, neste "princípio" de Galileu, se vislumbra o que hoje chamamos de conservação de energia, na medida em que, sendo iguais as alturas de $D E, D F$ e $D G$, são também iguais as energias potenciais em $D$ e, consequentemente, a energia cinética e a velocidade em $E, F$ e $G$.

Obviamente, foge ao alcance do presente trabalho pretender reconstituir a trajetória de Galileu das páginas finais de As mecânicas até a ciência madura do movimento publicada nos Discorsi. O que se quer aqui é sugerir que As mecânicas são, ao mesmo tempo, rigorosas, acabadas e prenhes de desenvolvimentos posteriores de Galileu e da física clássica. $\mathrm{O}$ objetivo do presente artigo já foi alcançado: percorrer as páginas de As mecânicas resumindo a estratégia e as táticas argumentativas de Galileu e apontando delas características especiais, características que não têm os textos escritos nos referenciais teóricos da física clássica. Como já se disse, isso foi feito no sentido de contribuir para uma leitura contemporânea da tradução apresentada a seguir. Portanto, nada se pode nem se deve fazer agora a não ser imediatamente remeter o leitor a esse momento fundador da ciência moderna.\$

\section{Julio Celso Ribeiro de Vasgongelos}

Professor Adjunto do Departamento de Ciências Humanas e Filosofia, Universidade Estadual de Feira de Santana, Bahia, Brasil. jul.ssa@gmail.com 


\section{ABSTRACT}

This article focuses on the theoretical developments of Mechanics, a pioneer work about the mechanical instruments written by Galileo Galilei $\left({ }_{1564},-164,2\right)$ in the 1590 's. This paper aims to point out to the contemporary reader the particularities of the concepts and arguments of Galileo's text, which are previous to the ones that constitute the so-called classical physics, in which the most of nowadays readers have been educated.

KeYwords • Balance. Lever, Statics. Dynamics. Mechanics. Galileo.

\section{REFERÊNGIAS BIBLIOGRÁFIGAS}

Favaro, A. (Ed.). Edizione nazionale delle opere di Galileo Galilei. Firenze: Barbera, 1933 [1891]. 20 v. (EN) Galilei, G. Le mecaniche. In: Favaro, A. (Ed.). Edizione nazionale delle opere di Galileo Galilei. Firenze: Barbera, 1933. v. 2, p. 155-90.

. Duas novas ciências. Tradução P. R. Mariconda \& L. Mariconda. São Paulo: Nova Stella, 1988.

Galluzzi, P. Momento: studi galileiani. Roma: Ateneo \& Bizzarri, 1979.

Gatto, R. Consideraciones sobre Las mecánicas de Galileo. In: Montesinos, J. (Ed.). Galileo y la gestación de la ciencia moderna. Canarias: Fundación Canaria Orotava de Historia de La Ciencia, 2001a. p. $187^{-203 .}$

Montesinos, J. (Ed.). Galileo y la gestación de la ciencia moderna. Canarias: Fundación Canaria Orotava de Historia de La Ciencia, 2001.

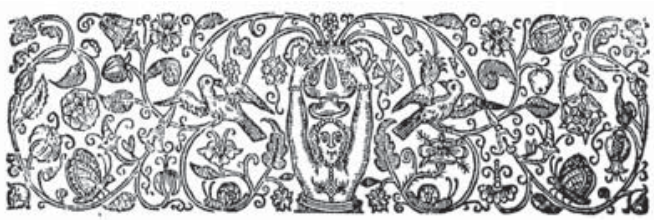

